\title{
Perencanaan Strategis Sistem Informasi/Teknologi Informasi Menggunakan Kerangka Kerja Business Canvas Model Dan Metode Ward \& Peppard
}

\section{Strategic Planning for Information System/Information Technology Using Business Canvas Model Framework And ward \& Peppard Method}

\author{
Elsa Melati Nurrachmat ${ }^{*}$, Hanif Fakhrurroja ${ }^{2}$ \\ ${ }^{1}$ Program Studi Sistem Informasi, Fakultas Manajemen Informatika, STIMIK LPKIA \\ ${ }^{2}$ UPT Balai Pengembangan Instrumentasi - LIPI
}

\section{ARTICLE INFO}

Article history:

Diterima 03-07-2019

Diperbaiki 10-10-2019

Disetujui 27-12-2019

\section{Kata Kunci:}

Ward dan Peppard, perencanaan strategis, Business Canvas Model, sistem informasi

Keywords:

Ward and Peppard, Strategic planning, Business Canvas Model, Business Model, Information system

\section{ABSTRAK}

Tingginya persaingan dalam industri air minum dalam kemasan menjadi sebuah tantangan besar bagi perusahaan yang bergerak dalam industri tersebut. Sebagai salah satu perusahaan air minum dalam kemasan yang sedang berkembang, CV.XYZ kini tengah bersiap dalam menghadapi tantangan persaingan yang ada dengan memanfaatkan sistem informasi dan teknologi informasi, namun perusahaan mengalami kesulitan dalam menetapkan sistem dan teknologi informasi yang paling tepat untuk dipergunakan sebagai senjata dalam memenangkan persaingan bisnis, maka dalam penelitian ini dilakukan berbagai tahap analisa dalam menyusun rencana strategis sistem informasi dan teknologi informasi dengan menggunakan metode Ward dan Peppard, disesuaikan dengan model bisnis perusahaan yang tengah berlangsung menggunakan kerangka kerja bussiness canvas model untuk melihat keterkaitan antara keduanya. Hasil dari penelitian ini berupa rekomendasi dalam portofolio aplikasi dan usulan rencana strategis sistem informasi yang nantinya dapat dipergunakan sebagai acuan bagi perusahaan dalam implementasi dan pengembangan sistem informasi dan teknologi informasi yang dapat meningkatkan daya saing perusahaan.

\begin{abstract}
A B S T R A C T
The high competition in the bottled drinking water industry has become a major challenge for companies engaged in the industry, and as one of the developing bottled drinking water companies, CV. Tirta Sakti is now preparing to face these challenges by utilizing information and technology systems. information, but companies experience difficulties in establishing the most appropriate information systems and technologies to be used as weapons in winning organizational business competition. so in this study various stages of analysis will be carried out in the formulation of strategic plans for information systems and information technology using the Ward and Peppard methods, adjusted to the ongoing business model of the company using the framework of the business canvas model to see the relationship between the two. The results of this study are recommendations and proposals for strategic plans that can later be used as a reference for companies in the implementation and development of information systems and information technology in the company
\end{abstract}

\section{Pendahuluan}

Organisasi bisnis saat ini khususnya dalam sektor industri air minum dalam kemasan (AMDK), dihadapkan dengan tantangan besar dalam persaingan usaha yang semakin ketat, tercatat pada tahun 2016 saja jumlah industri air minum dalam kemasan di dalam negeri telah mencapai 700 unit dengan 2.000 merek [1], fenomena persaingan tersebut tentu menuntut organisasi bisnis dalam sektor ini untuk benar-benar mempersiapkan segala macam strategi yang dapat meningkatkan daya saing perusahaan [2].
Berkaitan dengan hal tersebut, banyak kini perusahaan yang mulai menerapkan sistem teknologi informasi sebagai senjata dalam bersaing, tetapi banyak dari mereka gagal mendapatkan keunggulan kompetitif yang diharapkan akibat dari sistem teknologi informasi yang tidak direncanakan dengan baik [3].

CV. XYZ merupakan salah satu perusahaan yang juga tengah menghadapi tantangan tersebut, perusahaan ini memproduksi air minum kesehatan dalam kemasan, dan mendistribusikannya ke wilayah-wilayah di indonesia, sejak 
berdiri pada akhir tahun 2008, CV.XYZ masih menggunakan cara-cara konvensional dalam menjalankan aktivitas pada strategi bisnisnya, hal tersebut masih dilakukan karena adanya kesulitan yang selama ini dihadapi oleh perusahaan dalam menentukan sistem informasi/teknologi informasi yang benarbenar sesuai dengan kebutuhan perusahaan. Hal itu juga diungkapkan oleh pihak perusahaan menjadi salah satu hambatan yang di alami CV.XYZ dalam memulai implementasi sistem informasi dan teknologi informasi untuk memenangkan persaingan bisnis yang dihadapi.

Mengacu pada fenomena dan permasalahan di atas, adapun penelitian-penelitian terdahulu yang membahas mengenai perencanaan strategis sistem informasi dengan pendekatan Ward \& Peppard, [4]; [5]; [6] dan penelitianpenelitian lainnya mengenai upaya dalam meningkatkan daya saing perusahaan dengan menggunakan kerangka kerja Business Canvas Model [7]; [8]; [9], namun berdasarkan hasil dari survei paper tersebut belum ditemukan adanya perencanaan strategis sistem informasi/teknologi informasi yang dikaitkan dengan analisis model bisnis perusahaan, padahal jika kedua hal tersebut dilakukan dapat memperkuat hasil yang ingin dicapai, selain itu penggunaan kedua pendekatan tersebut juga dapat menunjukan seberapa besar radikal perubahan yang akan dilakukan dan konsekuensinya [9]. Berdasarkan hal tersebut selanjutnya timbul pertanyaan tentang bagaimana perencanaan strategis sistem informasi dan teknologi informasi dapat dilakukan untuk mendukung daya saing perusahaan dengan mengacu pada model bisnis yang ada ?.

Penelitian ini bertujuan menghasilkan perencanaan strategis SI/TI untuk mendukung daya saing perusahaan dengan mengacu pada model bisnis perusahaan yang tengah berjalan, karna dengan terlebih dahulu mengetahui model bisnis saat ini, perusahaan akan dapat memahami pada blok mana dalam model bisnisnya, teknologi dan sistem informasi perlu diutamakan, dan teknologi seperti apa yang diperlukan untuk menunjangnya. Selain itu penelitian ini juga menjabarkan hasil analisa keterkaitan antara model bisnis perusahaan dengan perencanaan strategis SI/TI untuk melihat sejauh mana perubahaan yang akan dilakukan.

Alat analisa yang digunakan dalam penelitian ini menggunakan Business Canvas Model sebagai kerangka kerja untuk menganalisa model bisnis perusahaan [11], karna dapat meberikan gambaran jelas dan terperinci mengenai Business elmen-elmen utama dalam membetuk model bisnis pada sebuah perusahaan, model bisnis sendiri seperti dikatakan oleh Oster dan Pigneur, adalah gambaran dasar pemikiran tentang bagaimana organisasi menciptakan, memberikan, dan menangkap nilai [12], adapun alat analisa dalam perencanaan strategis SI/TI menggunakan metode ward\&peppard karna sesuai dengan bidang pendidikan, dan memiliki tahapan analisis yang lengkap mulai dari adanya analisis mengenai faktor internal dan eksternal perusahaan serta analisis mengenai faktor SI/TI internal dan eksternal perusahaan, sehingga dapat memudahkan penelitan dalam memahami kondisi perusahaan saat ini.

Selanjutnya dari penelitian ini diharapkan dapat meberikan manfaat sebagai tambahan referensi bagi peneliti lain dalam menyusun rencana strategis yang dapat mendukung perusahaan dalam memenangkan persaingan bisnis

menggunakan sistem informasi dan tekologi informasi.

\section{Metode Penelitian}

Dalam penelitian ini metode yang digunakan di susun ke dalam sebuah kerangka penelitian sebagaimana diperlihatkan pada Gambar 1., yang didalamnya mencangkup tahapantahapan dalam menyusun penelitian.

Teknik pengumpulan data pada penelitian ini menggunakan Metodologi kualitatif yang diantaranya melalui studi dokumen, studi lapangan, studi litelatur dan wawancara, kemudian setelah didapat data yang diperlukan, selanjutnya dilakukan analisa model bisnis dengan menggunakan kerangka kerja Business canvas model, sebuah alat yang digunakan untuk mendeskripsikan sembilan kotak yang masing-masing merepresentasikan elemen-elmen kunci yang secara umum saling berpengaruh dalam menggambarkan model bisnis perusahaan. Kesembilan elmen tersebut diantaranya adalah Segmen Pelanggan, Proposisi Nilai, Saluran Komunikasi, Hubungan Pelanggan, Arus Pendapatan, Sumberdaya Utama, Aktivitas Kunci, Kemitraan Utama, dan Struktur Biaya [12]

Setelah model bisnis saat ini teridentifikasi, dilanjutkan dengan melakukan perencanaan strategis menggunakan metode Ward dan Peppard dimana dalam metode tersebut keempat lingkungan perusahaan dianalisis menggunakan alat analisis seperti PEST, matriks SWOT, Balanced scoredcard, Critical success factor dan Rantai Nilai, masing-masing alat analisis tersebut mengeluarkan hasil yang saling berkaitan dalam menghasilkan rencana strategis berupa usulan strategi bisnis SI, strategi manajemen SI/TI, dan strategi TI, juga termasuk didalamnya rekomendasi usulan SI/TI dalam portofolio aplikasi, hasil dari rekomendasi SI/TI selanjutnya di analisa kembali untuk mengetahui seberapa besar pengaruhnya terhadap model bisnis perusahaan. setelah itu barulah dibuat roadmap kegiatan yang dapat dijadikan acuan bagi pengembangan dan implementasi dari usulan strategi yang direkomendasikan.

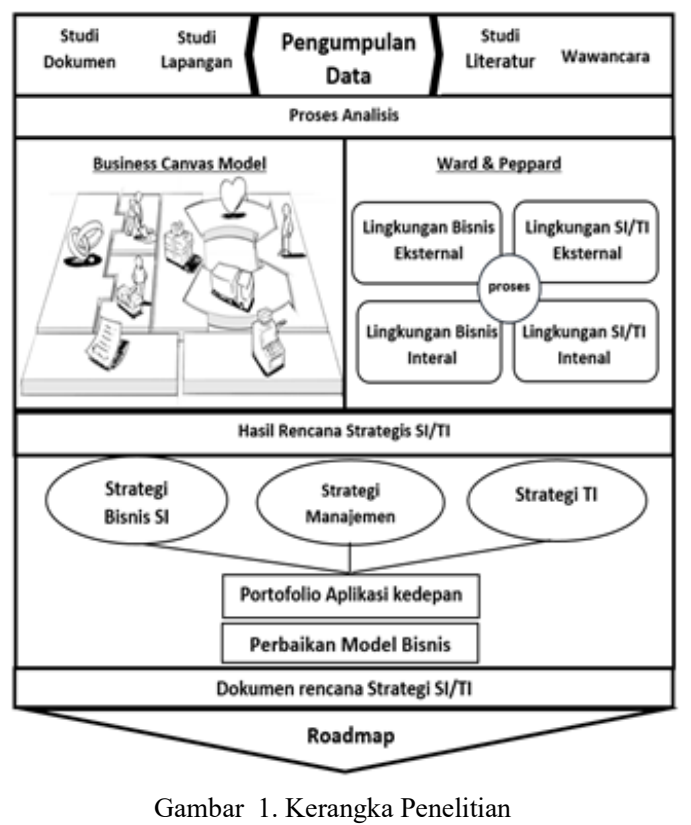




\section{Hasil dan Pembahasan}

Seperti yang telah disebutkan sebelumnya CV. XYZ adalah perusahaan yang bergerak dalam industri air minum dalam kemasan yang memfokuskan prodaknya pada air minum kesehatan, yang memiliki visi dan misi sebagai berikut.

Visi :

- Menjadi perusahaan air minum kesehatan terpercaya di indonesia.

- Menjadi bagian dari keluarga sehat Indonesia.

$\underline{\text { Misi }}$

- Meningkatkan dan mengembangkan keunggulan bersaing dengan memperkuat citra produk sesuai segmen yang telah ditetapkan

- Meningkatkan kualitas pelayanan sesuai dengan kebutuhan pelanggan

- Memperluas jangkauan pemasaran

Selanjutnya setelah mengetahui visi dan misi perusahaan, dilakukan analisa model bisnis yang tengah berjalan saat ini untuk mengetahui apakah visi serta misi yang ditetapkan sudah sesuai dengan model bisnis yang dijalankan.

\subsection{Model Bisnis Perusahaan}

Hasil dari analisis model bisnis perusahaan yang dilakukan dapat dilihat pada Gambar 2 Identifikasi Model Bisnis Saat ini. Berdasarkan gambar tersebut dapat diketahui bagaimana cara perusahaan pada kondisi saat ini dalam menghasilkan uang [10], selain itu terlihat adanya kelemahan yang sangat terlihat pada blok hubungan pelanggan dan saluran komunikasi, dimana dalam blok hubungan pelanggan tidak meperlihatkan adanya usaha yang dilakukan perusahaan untuk menjalin hubungan langsung dengan konsumen akhir, selain itu adapun saluran komunikasi yang dilakukan saat ini masih dilakukan dengan cara yang konvensional, sehingga hal tersebut menjadi faktor yang harus dipertimbangkan untuk dilakukan perbaikan. Selanjutnya hasil dari identifikasi BCM dipergunakan kembali sebagai masukan pada analisis Matriks SWOT.

\subsection{Analisis PEST}

Analisis politik, ekonomi, sosial, dan teknologi (PEST), dilakukan untuk menilai keadaan lingkungan eksternal perusahaan, didapat dari isu-isu yang sedang berkembang yang secara langsung dapat mempengaruhi bisnis organisasi.

Analisis PEST dalam penelitian ini menghasilkan gambaran tentang peluang dan ancaman yang dihadapi oleh perusahaan, selanjutnya hasil tersebut dijadikan sebagai masukan yang digunakan dalam analisis pada matriks SWOT.
Tabel 1.

Analisis PEST

\begin{tabular}{|l|l|}
\hline \multicolumn{1}{|c|}{ Politik } & \multicolumn{1}{c|}{ Sosial } \\
\hline $\begin{array}{l}\text { Pembatalan UU No 7 Thn 2004, } \\
\text { Tentang pengelolaan SDA. } \\
\text { PMK no } 19 / 2009 \text { tentang } \\
\text { penetapan tarif bea masuk barang } \\
\text { impor seperti plastik. }\end{array}$ & $\begin{array}{l}\text { Tren pola hidup sehat marak } \\
\text { dikampnyeukan. } \\
\text { Populasi terus meningkat } \\
\text { berdampak pada konsumsi air } \\
\text { minum dalam kemasan dalam } \\
\text { negeri ikut meningkat. }\end{array}$ \\
\hline \multicolumn{1}{|c|}{ Ekonomi } & \multicolumn{1}{|c|}{ Teknologi } \\
\hline $\begin{array}{l}\text { Peka terhadap Nilai tukar rupiah } \\
\text { terkait impor plastic } \\
\text { Kegiatan distribusi Peka } \\
\text { terhadap kenaikan harga BBM \& } \\
\text { Upah tenaga kerja }\end{array}$ & $\begin{array}{l}\text { Penggunaan tekonlogi logistik } \\
\text { oleh industri besar AMDK. } \\
\text { Daya beli masyarkat meningkat } \\
\text { setiap tahun internet meningkat }\end{array}$ \\
$\begin{array}{l}\text { smartphone menjadi pilihan } \\
\text { terbesar bagi masyarakat dalam } \\
\text { mengakses internet }\end{array}$ \\
\hline
\end{tabular}

\subsection{Matriks SWOT}

Setelah mendapatkan beberapa informasi melalui wawancara, identifikasi Model Bisnis saat ini, dan analisis PEST, didapatkan analisa mengenai kekuatan, kelemahan, peluang dan ancaman yang dihadapi perusahaan, diantaranya seperti terlihat pada Tabel 2 .

Tabel 2

Analisis SWOT

\begin{tabular}{|c|c|}
\hline $\operatorname{th}(S)$ & Weaknes $(W)$ \\
\hline $\begin{array}{l}\text { Target konsumen jelas dan } \\
\text { spesifik. } \\
\text { Proposisi nilai spesifik } \\
\text { menjawab kebutuhan masing- } \\
\text { masing segmen yang dibidik. } \\
\text { Memiliki diferensiasi nilai } \\
\text { prodak yang ditawarkan yang } \\
\text { mana belum pernah } \\
\text { ditawarkan oleh kompetitor } \\
\text { lain. } \\
\text { Memiliki konsumen yang } \\
\text { loyal. } \\
\text { Legalitas usaha. } \\
\text { Memiliki tempat produksi } \\
\text { yang dekat dengan sumber } \\
\text { mata air. }\end{array}$ & \begin{tabular}{|l|} 
- \\
Promosi belum maksimal \\
sehingga banyak orang yang \\
belum tau mengenai prodak \\
perusahaan. \\
Komunikasi yang dilakukan masih \\
berupa hubungan antara \\
perusahaan dengan distributor, \\
sedangkan perusahan dengan \\
konsumen akhir belum dilakukan. \\
Standar ukuran kerja yang harus \\
dilakukan oleh tenaga marketing \\
dan penjualan masih kurang jelas. \\
Belum terkelolanya data dan arus \\
informasi perusahaan. \\
keluhan pelanggan belum \\
terkelola.
\end{tabular} \\
\hline Oppor & \\
\hline $\begin{array}{l}\text { Potensi pasar AMDK terus } \\
\text { berkembang. } \\
\text { Meningkatnya daya beli } \\
\text { masyarakat untuk } \\
\text { mengkonsumsi air minum } \\
\text { dalam kemasan. } \\
\text { Tren pola hidup sehat, sedang } \\
\text { diminati masyarakat. } \\
\text { Ketersediaan teknologi } \\
\text { internet yang semakin meluas. } \\
\text { Besarnya jumlah Pengguna } \\
\text { Smartphone }\end{array}$ & 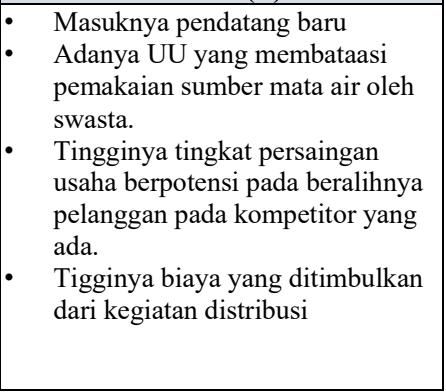 \\
\hline
\end{tabular}




\begin{tabular}{|c|c|c|c|c|}
\hline \multirow[t]{2}{*}{$\begin{array}{l}\text { Mitra Utama } \\
\text { Bahan Baku Air } \\
\text { Pemasok material } \\
\text { (botol plastik, karton, } \\
\text { seal) }\end{array}$} & $\begin{array}{|ll|}\text { Aktifitas Utama } \\
\text { - } & \text { Kegiatan marketing } \\
& \text { untuk konsumen akhir } \\
& \text { dan calon } \\
& \text { agen/distributor } \\
\cdot & \text { Pengontrolan proses } \\
& \text { produksi } \\
\end{array}$ & $\begin{array}{l}\text { Proposisi Nilai } \\
\text { Segmen 1.A. } \\
\text { air minum kesehatan } \\
\text { dengan molekul } \\
\text { microcluster }\end{array}$ & \begin{tabular}{|l|} 
Hubungan \\
Pelanggan \\
pemberian hadiah di hari \\
raya untuk para \\
distributor.
\end{tabular} & \multirow{2}{*}{$\begin{array}{l}\text { Segmen } \\
\text { Pelanggan } \\
\text { 1.Konsumen Akhir } \\
\text { A. Orang-orang di usia 40- } \\
55, \text { yang memerlukan } \\
\text { alternatif produk } \\
\text { kesehatan dalam } \\
\text { mengatasi keluhan } \\
\text { kesehatannya } \\
\text { B. Keluarga yang konsern } \\
\text { terhadap pola hidup } \\
\text { sehat. } \\
\text { 2. Calon Distributor } \\
\text { orang-orang yang ingin } \\
\text { mendapatkan penghasilan dari } \\
\text { menjual produk perusahaan }\end{array}$} \\
\hline & $\begin{array}{l}\text { Sumber Daya } \\
\text { Utama } \\
\text { - Kapabilitas tenaga } \\
\text { marketing dan penjualan } \\
\text { - Sumberdaya pada bagian } \\
\text { produksi } \\
\text { - Legalitas }\end{array}$ & $\begin{array}{l}\text { Segmen 1.B. } \\
\text { Air dengan PH Netral, } \\
\text { aman dan layak konsumsi } \\
\text { untuk segala usia } \\
\text { Segmen 2 } \\
\text { Peluang menjadi agen / } \\
\text { distributor perusahaan }\end{array}$ & $\begin{array}{l}\text { Saluran } \\
\text { Komunikasi } \\
\text { - Penjualan langsung } \\
\quad \text { (direct selling) } \\
\text { - Distributor keagenan } \\
\text { - Brosur } \\
\text { - Spanduk }\end{array}$ & \\
\hline $\begin{array}{l}\text { Struktur Biaya } \\
\text { - } \quad \text { Biaya oprasional } \\
\text { - Biaya Distribusi }\end{array}$ & & $\begin{array}{r}\text { Aliran pen } \\
\text { - } \quad \begin{array}{r}\text { Penjual } \\
\text { agen/di }\end{array}\end{array}$ & $\begin{array}{l}\text { dapatan } \\
\text { n prodak air minum dalam ken } \\
\text { ributor. }\end{array}$ & asan melalui \\
\hline
\end{tabular}

Gambar 2. Identifikasi Model Bisnis Saat ini

Selanjutnya peluang dan ancaman yang dihadapi perusahaan disesuaikan dengan kekuatan serta kelemahan yang dimiliki [13], sehingga menghasilkan formula strategi, seperti terlihat pada Tabel 3. Hasil Analisis SWOT.

Tabel 3.

Hasil Analisis SWOT

\begin{tabular}{|c|c|}
\hline Formula strategi & Tujuan strategi \\
\hline \begin{tabular}{|l|} 
Perusahaan perlu membangun citra \\
produk agar proposisi nilai lebih \\
tertanam di benak konsumen $(\mathrm{O} 1, \mathrm{~S} 1)$ \\
$(\mathrm{O} 2, \mathrm{~S} 3),(\mathrm{O} 3, \mathrm{~S} 2)$
\end{tabular} & $\begin{array}{l}\text { Memperkuat identitas } \\
\text { merek perusahaan }\end{array}$ \\
\hline 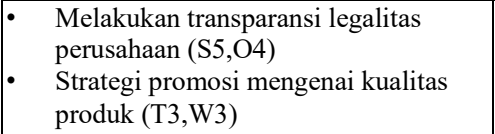 & $\begin{array}{l}\text { Meyakinkan pelanggan } \\
\text { dengan Kualitas }\end{array}$ \\
\hline $\begin{array}{l}\text { Mengelola konsumen akhir melalui } \\
\text { dibentuknya komunitas melalui } \\
\text { pemanfaatan sosial media }(\mathrm{S} 4, \mathrm{O} 4) \text {. }\end{array}$ & 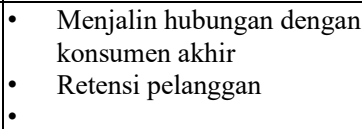 \\
\hline $\begin{array}{l}\text { Menjadikan Penggunaan internet } \\
\text { sebagai salah satu media promosi yang } \\
\text { efektif dengan biaya murah (W1,O4, } \\
\text { O5). }\end{array}$ & $\begin{array}{ll}\text { - } & \text { Efesiensi biaya } \\
\text { Meningkatkan margin } \\
\text { perusahaan }\end{array}$ \\
\hline $\begin{array}{ll}- & \text { Menjadikan data pelanggan sebagai } \\
\text { aset perusahaan (W4) } \\
\text { Menyediakan sarana pengaduan } \\
\text { konsumen (W5,W4,O4) }\end{array}$ & $\begin{array}{l}\text { Meningkatkan kepuasan } \\
\text { pelanggan. }\end{array}$ \\
\hline $\begin{array}{l}\text { Mengidentifikasi pelatihan yang tepat } \\
\text { untuk tenaga marketing dan penjualan } \\
\text { berhubungan dengan pemanfaatan } \\
\text { digital marketing melalui perangkat } \\
\text { mobile dan internet (W3,O4,O5). }\end{array}$ & $\begin{array}{l}\text { Melakukan rekrutmen } \\
\text { dibidang IT } \\
\text { Melakukan pelatihan } \\
\text { keahlian SDM }\end{array}$ \\
\hline $\begin{array}{ll} & \text { Mengelola data dan informasi strategis } \\
(\mathrm{T} 3, \mathrm{~T} 4, \mathrm{~W} 4)\end{array}$ & $\begin{array}{ll}\text { Meningkatkan kualitas } \\
\text { informasi dan database } \\
\text { perusahaan. } \\
\text { Pengembangan \& } \\
\text { pemanfaatan SI/TI }\end{array}$ \\
\hline $\begin{array}{l}\begin{array}{l}\text { Melakukan kemitraan dengan BUMN } \\
\text { atau BUMD terhadap pemenuhan } \\
\text { bahan baku air }(\mathrm{S} 6, \mathrm{~T} 2)\end{array} \\
\end{array}$ & $\begin{array}{l}\text { Menjaga ketersediaan } \\
\text { bahan baku }\end{array}$ \\
\hline \begin{tabular}{ll|} 
- & Melakukan upaya dalam program \\
akusisi, dan retensi pelanggan $(\mathrm{W} 1, \mathrm{~T} 1)$
\end{tabular} & - Meningkatkan penjualan \\
\hline
\end{tabular}

\begin{tabular}{|c|c|}
\hline Formula strategi & Tujuan strategi \\
\hline $\begin{array}{l}\text { Menggunakan teknologi internet dan } \\
\text { sosial media sebagai sarana promosi } \\
\text { dengan jangkauan yang luas } \\
\text { (W4,O4,O5). }\end{array}$ & \\
\hline $\begin{array}{l}\text { - } \begin{array}{l}\text { Mengimplementasikan rantai nilai } \\
\text { pasok pada kegiatan pengadaan bahan } \\
\text { baku. }(\mathrm{T} 4, \mathrm{~W} 5)\end{array}\end{array}$ & $\begin{array}{l}\text { - } \begin{array}{l}\text { Meningkatkan kualitas } \\
\text { produksi }\end{array} \\
\text { - }\end{array}$ \\
\hline
\end{tabular}

\subsection{Balanced Scored Card}

Analisa Balanced Scored Card (BSC), dipergunakan untuk menerjemahkan visi, misi dan tujuan strategi ke dalam 4 perspektif yang terdiri dari finansial, pelanggan, proses bisnis internal serta pembelajaran dan pertumbuhan [14]. Hasil analisa Balanced Scored card dalam penelitian ini dapat dilihat pada Tabel 4.

Tabel 4.

Balacned Scored Card

\begin{tabular}{|c|c|c|}
\hline Perspektif & Tujuan Setiap Prespektif & Ukuran \\
\hline \multirow{3}{*}{ 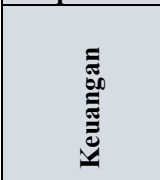 } & Meningkatkan penjualan & Jumlah penjulan meningkat \\
\hline & $\begin{array}{l}\text { Meningkatkan margin } \\
\text { perusahaan }\end{array}$ & Keuntungan Meningkat \\
\hline & Efesiensi biaya & Biaya oprasional turun \\
\hline \multirow{5}{*}{ 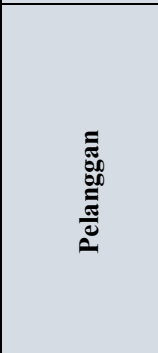 } & Retensi pelanggan & Jumlah pembelian ulang \\
\hline & $\begin{array}{l}\text { Menjalin hubungan dengan } \\
\text { pelanggan }\end{array}$ & $\begin{array}{l}\text { Jumlah interaksi yang masuk } \\
\text { berupa saran, } \\
\text { komentar,testimoni }\end{array}$ \\
\hline & \begin{tabular}{|lr|}
\multicolumn{2}{|l|}{ Meyakinkan pelanggan } \\
dengan kualitas prodak \\
dengan pelayanan
\end{tabular} & Menurunnya Jumlah keluhan \\
\hline & Memperkuat identitas merek & Hasil survey dalam Kuisioner \\
\hline & $\begin{array}{l}\text { Menciptakan } \\
\text { kepuasan pelanggan }\end{array}$ & $\begin{array}{l}\text { Hasil survey kepuasan } \\
\text { pelanggan }\end{array}$ \\
\hline  & Pemanfaatan SI/TI & $\begin{array}{l}\text { Kecepatan waktu dalam } \\
\text { menyelesaikan pekerjaan }\end{array}$ \\
\hline
\end{tabular}




\begin{tabular}{|c|c|c|}
\hline Perspektif & Tujuan Setiap Prespektif & Ukuran \\
\hline & $\begin{array}{l}\text { Meningkatkan kualitas } \\
\text { produksi }\end{array}$ & $\begin{array}{l}\text { Persentase tingkat penurunan } \\
\text { kesalahan produksi }\end{array}$ \\
\hline & $\begin{array}{l}\text { Menjaga ketersediaan } \\
\text { bahan baku }\end{array}$ & $\begin{array}{l}\text { Persentase ketepatan dalam } \\
\text { pengelolaan inventori }\end{array}$ \\
\hline & $\begin{array}{l}\text { Meningkatkan kualitas } \\
\text { informasi }\end{array}$ & $\begin{array}{l}\text { Kecepatan waktu akses } \\
\text { informasi }\end{array}$ \\
\hline \multirow{2}{*}{ 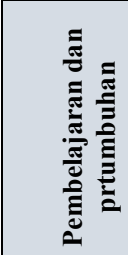 } & $\begin{array}{l}\text { Melakukan rekrutmen di } \\
\text { bidang IT }\end{array}$ & $\begin{array}{l}\text { peningkatan kemampuan } \\
\text { pengelolaan SI/TI }\end{array}$ \\
\hline & Pelatihan keahllian & $\begin{array}{l}\text { Jumlah pelatihan yang } \\
\text { dilakuakan }\end{array}$ \\
\hline
\end{tabular}

Hasil dari analisis balanced scorecard pada Tabel 4, menghasilkan uraian mengenai tujuan dan ukuran yang perlu diacapai pada masing-masing perspektif.

\subsection{Critical Success Factor}

Setelah didapatkan hasil dari berbagai analisis seperti BCM, PEST, SWOT dan BSC maka selanjutnya dilakukan analisis CSF, untuk meganalisa faktor-faktor apa saja yang harus lakukan untuk mencapai tujuan pada masing-masing perspektif yang diharapkan, hasil analisis tersebut dapat terlihat pada Tabel 5 .

Tabel 5

Critical Sucess Factor

Faktor kritis Perspektif Keuangan

\begin{tabular}{|c|}
\hline Faktor kritis Perspektif Keuangan \\
\hline Ketepatan alokasi biaya oprasional \\
\hline perluasan jangkauan pemasaran dan pertambahan distributor \\
\hline Marketing tepat sasaran \\
\hline Pengembangan \& penerapan SI/TI yang tepat sesuai kebutuhan. \\
\hline Faktor kritis Perspektif pelanggan \\
\hline Tersampaikannya setiap keluhan mengenai prodak dan pelayanan. \\
\hline Respon cepat terhadap keluhan yang disampaikan \\
\hline Faktor kritis Perspektif pelanggan \\
\hline Adanya feedback (umpan balik) dari pelanggan maupun distributor. \\
\hline $\begin{array}{l}\text { Ketersediaan sarana informasi yang menjembatani pelanggan dan } \\
\text { perusahaan dalam menjelaskan mengenai kualitas prodak. }\end{array}$ \\
\hline
\end{tabular}

\begin{tabular}{|l|}
\hline $\begin{array}{l}\text { Kegiatan marketing harus mempu menyampaikan informasi mengenai } \\
\text { keunggulan prodak. }\end{array}$ \\
\hline Kemudahan pelanggan dalam mendapatkan prodak. \\
\hline \multicolumn{1}{c|}{ Faktor Kritis Perspektif Proses bisnis internal } \\
\hline Memastikan seluruh kegiatan produksi berjalan sesuai dengan SOP. \\
\hline Pemahaman akan kebutuhan informasi \\
\hline Kemampuan dalam pengelolaan SI/TI \\
\hline $\begin{array}{l}\text { Kemampuan Pengelolaan data pada setiap devisi dalam menghasilkan } \\
\text { informasi strategis perusahaan }\end{array}$ \\
\hline $\begin{array}{l}\text { Alur informasi yang cepat dan tepat mengenai permintaan barang sampai } \\
\text { dengan tahap pendistribusian }\end{array}$ \\
\hline $\begin{array}{l}\text { Kemampuan devisi produksi dalam mnjadwalkan produksi dengan } \\
\text { kebutuhan bahan baku. }\end{array}$ \\
\hline \multicolumn{1}{c|}{ Faktor Kritis Perspektif pembelajaran \& pertumbuhan } \\
\hline $\begin{array}{l}\text { Adanya analisa kebutuhan sumberdaya manusia, dan kejelasan standar } \\
\text { oprasional yang harus dilaksanakan. }\end{array}$ \\
\hline Ketersediaan trainer berpengalaman. \\
\hline
\end{tabular}

\subsection{Rantai Nilai}

Berdasarkan hasil pengamatan langsung di perusahaan, wawancara dan analisis kondisi bisnis internal yang telah dilakukan, didapatkan beberapa aktivitas primer CV. XYZ yang terdiri dari aktivitas logistik kedalam, operasi, logistik keluar, pemasaran \& penjualan, dan pelayanan, setelah itu maka selanjutnya pada tahap ini dilakukan analisa mengenai bagaimana kegiatan-kegiatan primer tersebut kedepannya harus dapat dijalankan dengan memberikan nilai tambah, maka dalam melakukan analisis rantai nilai pada CV. XYZ, dilakukan analisa terhadap aktifitas pendukung yang dapat dilakukan untuk dapat memberikan nilai tambah kedalam aktifitas primer yang berlangsung, seperti dapat terlihat pada Gambar 3.

\subsection{Analisis Lingkungan SI/TI Eksternal}

Pada tahap ini analisis lingkungan SI/TI eksternal dilakukan dengan mengamati tren teknologi dan sistem informasi yang memiliki potensi untuk di implementasikan pada perusahaan CV.XYZ, dan beberapa diantaranya adalah tren teknologi mengenai aplikasi sistem informasi di industri Air minum dalam kemasan, tren penggunaan website, sosial media, dan cloud computing. Hasil dari tahap ini menjadi bahan acuan sebagai referensi dalam menentukan usulan SI/TI pada tahap selanjutnya. 


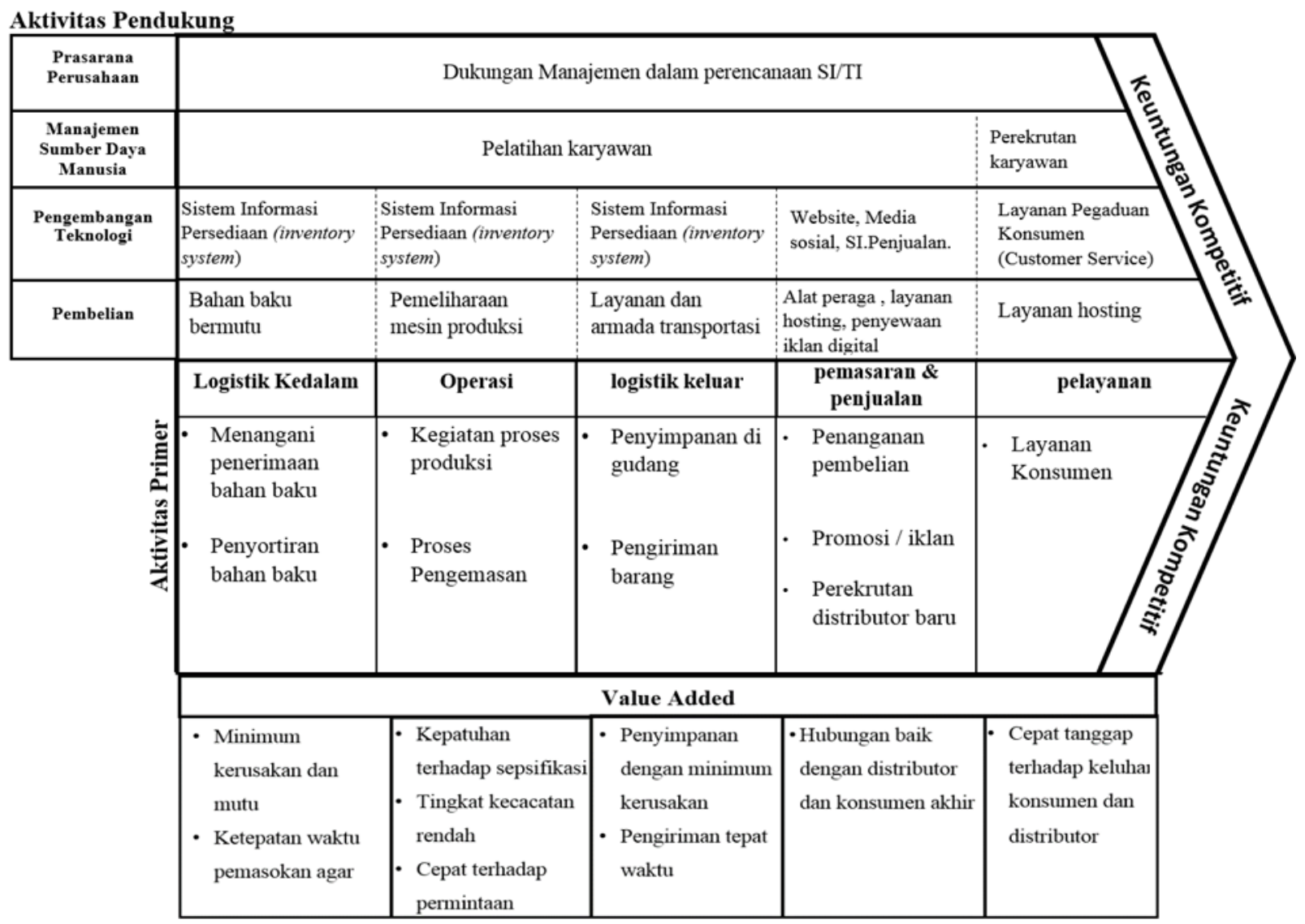

Gambar 3. Analisis Rantai Nilai

\subsection{Analisis Lingkungan SI/TI Internal}

Berdasarkan dari hasil analisa yang dilakukan melalui pengamatan langsung dilapangan, didapatkan beberapa aplikasi yang sudah berjalan diperusahaan, dan dapat terlihat pada Tabel 6.

Tabel 6.

Aplikasi Yang Tersedia Saat Ini

\begin{tabular}{|l|l|}
\hline \multicolumn{1}{|c|}{ Nama Aplikasi } & \multicolumn{1}{|c|}{ Fungsi } \\
\hline $\begin{array}{l}\text { Aplikasi penjualan (untuk } \\
\text { bagian penjualan dengan } \\
\text { distributor) }\end{array}$ & $\begin{array}{l}\text { digunakan sebagai alat pengelolaan } \\
\text { transaksi penjualan. }\end{array}$ \\
\hline Aplikasi keuangan & $\begin{array}{l}\text { Digunakan untuk mecatat kegiatan- } \\
\text { kegitan transaksi yang terjadi } \\
\text { diperusahaan. }\end{array}$ \\
\hline $\begin{array}{l}\text { Aplikasi persediaan } \\
\text { barang }\end{array}$ & $\begin{array}{l}\text { Digunakan untuk mencatat barang } \\
\text { yang selesai diproduksi juga barang } \\
\text { yang telah terjual. }\end{array}$ \\
\hline
\end{tabular}

\subsection{Strategi manajemen SI/TI}

Strategi manajemen SI/TI adalah strategi yang terkait dengan pengelolaan SI/TI dalam suatu organisasi. Strategi manajemen SI/TI perlu disusun dan di implementasikan untuk mencapai visi dan misi dalam pengembangan SI/TI, untuk itu salah satu langkah awal dalam implementasi SI/TI di perusahaan adalah diusulkannya struktur organisasi baru dengan menambahkan devisi yang khusus menangani SI/TI [15].

\subsection{Strategi Bisnis SI}

Menurut Ward dan Peppard, strategi bisnis si adalah tentang bagaimana setiap Fungsi di dalam perusahaan dapat mengimplementasikan SI/TI untuk mencapai tujuan bisnis organisasi. Maka hasil dari analisis Critical Success faktor yang telah dilakukan pada setiap perspektif dan ukuran pada analisis Balanced Scorecard, di analisa kembali untuk menentukan kebutuhan informasi dalam mendukung faktorfaktor tersebut, selanjutnya kebutuhan informasi yang dihasilkan dipetakan pada masing-masing Fungsi bisnis yang ada diperusahaan, dilanjutkan dengan dilakukan analsisis kebutuhan SI/TI yang dapat mendukung ketersediaan kebutuhan informasi. Hasil dari analisa pada tahap ini diuraikan dalam Tabel 7.

Tabel 7.

Strategi Bisnis SI

\begin{tabular}{|c|c|}
\hline \multicolumn{2}{|c|}{ Top Manajemen } \\
\hline Kebutuhn Informasi & Kebutuhan SI/TI \\
\hline $\begin{array}{l}\text { Laporan hasil kinerja } \\
\text { perusahaan }\end{array}$ & Dashboard information system \\
\hline \multicolumn{2}{|c|}{ Devisi Marketing dan penjualan } \\
\hline Kebutuhn Informasi & Kebutuhan SI/TI \\
\hline Data Konsumen, data & Aplikasi yang dapat merekap \\
\hline
\end{tabular}




\begin{tabular}{|c|c|}
\hline distributor & data konsumen dan distributor \\
\hline informasi wilayah pemasaran & $\begin{array}{l}\text { Aplikasi pemetaan wilayah } \\
\text { pemasaran }\end{array}$ \\
\hline Laporan penjualan & $\begin{array}{l}\text { Bottom of Form } \\
\text { Sistem informasi penjualan }\end{array}$ \\
\hline Grafik permintaan barang & $\begin{array}{l}\text { Aplikasi penjualan, distributor } \\
\text { terhadap konsumen akhir }\end{array}$ \\
\hline $\begin{array}{l}\text { Informasi Pengukuran tingkat } \\
\text { kepuasan pelanggan }\end{array}$ & $\begin{array}{l}\text { Aplikasi untuk menghitung } \\
\text { kepuasan pelanggan }\end{array}$ \\
\hline $\begin{array}{l}\text { Informasi mengenai jumlah } \\
\text { keluhan yang masuk beserta } \\
\text { waktu penyelesaiannya }\end{array}$ & $\begin{array}{l}\text { Aplikasi pelayanan dan } \\
\text { pengaduan konsumen }\end{array}$ \\
\hline \multicolumn{2}{|c|}{ Devisi Marketing dan penjualan } \\
\hline Kebutuhn Informasi & Kebutuhan SI/TI \\
\hline $\begin{array}{l}\text { Informasi mengenai testimoni, } \\
\text { dan antusias target market } \\
\text { terhadap produk. }\end{array}$ & $\begin{array}{l}\text { Penggunaan sosial media dan } \\
\text { Website }\end{array}$ \\
\hline $\begin{array}{l}\text { Informasi mengenai segala hal } \\
\text { tentang kualitas produk }\end{array}$ & Website Perusahaan \\
\hline $\begin{array}{l}\text { Informasi kepuasan pelangan } \\
\text { dan distributor }\end{array}$ & $\begin{array}{l}\text { Aplikasi Survei Kepuasan } \\
\text { pelangan }\end{array}$ \\
\hline Data penjualan barang & $\begin{array}{l}\text { Aplikasi penjualan pada bagian } \\
\text { penjualan terhadap distributor. }\end{array}$ \\
\hline \multicolumn{2}{|c|}{ Logistik } \\
\hline Kebutuhn Informasi & Kebutuhan SI/TI \\
\hline $\begin{array}{l}\text { Informasi permintaan } \\
\text { pengiriman, Jadwal pengiriman, } \\
\text { alamat pengiriman, jumlah } \\
\text { barang yang diangkut dalam } \\
\text { sekali pegiriman, informasi } \\
\text { pengiriman yang telah } \\
\text { diselesaikan. }\end{array}$ & $\begin{array}{l}\text { Sistem informasi pengiriman } \\
\text { barang (Global Potitioning } \\
\text { system) }\end{array}$ \\
\hline \multicolumn{2}{|c|}{ Keuangan } \\
\hline Kebutuhn Informasi & Kebutuhan SI/TI \\
\hline $\begin{array}{l}\text { Seluruh laporan pengeluaran, } \\
\text { laporan pemasukan, dan piutang } \\
\text { perusahaan. }\end{array}$ & Sistem informasi Keuangan \\
\hline \multicolumn{2}{|c|}{ Produksi } \\
\hline Kebutuhn Informasi & Kebutuhan SI/TI \\
\hline $\begin{array}{l}\text { Informasi ketersediaan bahan } \\
\text { baku } \\
\text { Informasi mengenai } \\
\text { perencanaan kebutuhan } \\
\text { produksi }\end{array}$ & $\begin{array}{l}\text { Sistem Informasi persediaan } \\
\text { dan pembelian bahan baku } \\
\text { (Inventory system) }\end{array}$ \\
\hline \multicolumn{2}{|l|}{ Gudang } \\
\hline Kebutuhn Informasi & Kebutuhan SI/TI \\
\hline $\begin{array}{l}\text { Data mengenai keluar masuk } \\
\text { barang, Stok, dan Permintaan } \\
\text { barang }\end{array}$ & $\begin{array}{l}\text { Sistem Informasi persediaan } \\
\text { barang (Inventory system) }\end{array}$ \\
\hline \multicolumn{2}{|c|}{ Devisi SI/TI } \\
\hline Kebutuhn Informasi & Kebutuhan SI/TI \\
\hline $\begin{array}{l}\text { Informasi pengelolaan } \\
\text { infrastruktur SI/TI }\end{array}$ & $\begin{array}{l}\text { Pengelolaan Infrastruktur } \\
(\text { Cloud/LAN })\end{array}$ \\
\hline
\end{tabular}

\subsection{Strategi TI}

Pada tahap ini hasil strategi TI menekankan pada pemilihan teknologi dan infrastruktur yang dibutuhkan organisasi, yang bertujuan untuk mendefinisikan sumber daya dan teknologi yang akan diperoleh, diatur, dan dikembangkan untuk menunjang strategi bisnis SI [16, 17]. Hasil tersebut diuraikan pada Tabel 8.
Tabel 8

Strategi Teknologi Informasi

\begin{tabular}{|c|c|c|}
\hline Usulan Aplikasi & Komponen Aplikasi & Infrastruktur TI \\
\hline $\begin{array}{l}\text { Pembangunan sistem } \\
\text { informasi berbasis } \\
\text { web }\end{array}$ & $\begin{array}{l}\text { Pengelolaan layanan dan } \\
\text { pengaduan konsumen } \\
\text { Pengelolaan } \\
\text { pelanggan } \\
\text {. Sebagai } \\
\text { perusahaan } \\
\text { Pengelolaan } \\
\text { Kepuasan pelangan } \\
\text { Fungsi purvei } \\
\text { penjualan pada distributor } \\
\text { terhadap konsumen akhir } \\
\text { Fungsi pengelolaan } \\
\text { penjualan pada bagian } \\
\text { penjualan terhadap } \\
\text { distributor } \\
\text { Pengelolaan Pemetaan } \\
\text { wilayah pemasaran } \\
\text { Fungsi pengelolaan Global } \\
\text { positioning system sebagai } \\
\text { media monitoring dalam } \\
\text { proses pengiriman barang } \\
\text { keoada distributor } \\
\text { Pengelolaan persediaan } \\
\text { barang }\end{array}$ & $\begin{array}{l}\text { Database software xampp } \\
\text { (MYSQL/Apache) } \\
\text { Akses internet } \\
\text { Layanan Web Hosting } \\
\text { Perangkat Mobile } \\
\text { Personal Computer }\end{array}$ \\
\hline $\begin{array}{l}\text { Pemanfaatan } \\
\text { marketing melalui } \\
\text { sosial media }\end{array}$ & $\begin{array}{l}\text { Kegiatan pengelolaan } \\
\text { digital marketing }\end{array}$ & $\begin{array}{l}\text { Perangkat Mobile } \\
\text { Personal Computer } \\
\text { Platform sosial media }\end{array}$ \\
\hline \begin{tabular}{|l} 
Dashboard \\
Information System
\end{tabular} & $\begin{array}{l}\text { Mengelola dan menyediakan } \\
\text { laporan hasil kinerja } \\
\text { masing-masing devisi }\end{array}$ & $\begin{array}{l}\text { Personal computer } \\
\text { Akses internet } \\
\text { Layanan Alih }\end{array}$ \\
\hline $\begin{array}{l}\text { Pengebangan Sistem } \\
\text { informasi keuangan }\end{array}$ & $\begin{array}{l}\text { Pengelolaan } \\
\text { kegiatan transaksi yang } \\
\text { terjadi pada perusahaan. }\end{array}$ & $\begin{array}{l}\text { Perangkat Lunak } \\
\text { Cloud Services }\end{array}$ \\
\hline
\end{tabular}

Adapun yang perlu diperhatikan dalam implementasi pengadaan infrastruktur IT diperusahaan adalah mengenai sejauh mana kesiapan perusahaan dalam melaksanakan implementasi tersebut, untuk itu rekomendasi usulan dalam strategi teknologi informasi adalah agar dilakukan pemanfaatan cloud computing dengan mengalih dayakan layanan, sebagai solusi dari penghematan biaya investasi pembelian perangkat keras, selain itu hal lainnya yang perlu diperhatikan yaitu mengenai kebijakan-kebijakan untuk mengelola sumber daya dan teknologi informasi yang harus tetap menjadi perhatian dalam perencanaan strategis SI/TI di perusahaan kedepannya.

\subsection{Portofolio aplikasi}

Berdasarkan usulan strategi bisnis SI yang ada, selanjutnya sistem Informasi yang menjadi rekomendasi, disusun kedalam portofolio untuk memetakan sistem kedalam empat kuadran yang masing-masing bersifat strategis, high potensial, oprational, dan support, yang berguna dalam mempermudah perusahaan dalam memahami sejauh mana SI/TI usulan dapat mendukung rencana strategis perusahaan dalam mendukung daya saing, seperti ditapilkan pada Tabel 9.

Tabel 9

Portofolio Aplikasi Usulan

\begin{tabular}{|c|c|}
\hline Strategic & High Potential \\
\hline $\begin{array}{lll} & \text { sistem layanan } \\
\text { pengaduan konsumen }\end{array}$ & $\begin{array}{l}\text { 1. Pemanfaatan cloud } \\
\text { computing }\end{array}$ \\
\hline 2. Sistem mengelolaan data & 2. Aplikasi pemetaan \\
\hline
\end{tabular}




\begin{tabular}{|c|c|}
\hline $\begin{array}{ll} & \text { pelanggan } \\
\text { 3. } & \text { Penggunaan sosial media } \\
\text { sebagai media marketing } \\
\text { 4. Website perusahaan } \\
\text { 5. Sistem untuk mengelola } \\
\text { Kepuasan pelangan } \\
\text { 6. Sistem Pengelolaan } \\
\text { penjualan pada distributor } \\
\text { kepada konsumen akhir } \\
\end{array}$ & $\begin{array}{l}\text { wilayah pemasaran } \\
\text { 3. Dashboard Information } \\
\text { System }\end{array}$ \\
\hline Key Oprational & Support \\
\hline $\begin{array}{llr}\text { 1. } & \begin{array}{c}\text { Sistem pengelolaan } \\
\text { penjualan pada bagian } \\
\text { penjualan } \\
\text { distributor }\end{array} \\
\text { 2. } & \begin{array}{l}\text { Sistem informasi keuangan } \\
\text { 3. }\end{array} \\
\text { Sistem informasi persediaan } \\
\text { (Inventory system) }\end{array}$ & $\begin{array}{ll}\text { 1. } & \text { Aplikasi pengiriman } \\
& \text { barang (Global } \\
& \text { positioning system) }\end{array}$ \\
\hline
\end{tabular}

\subsection{Perbaikan model bisnis}

Berdasarkan hasil dari perencanaan strategi SI/TI perusahaan, dapat dilihat pengaruhnya terhadap model bisnis yang sedang berjalan, sehingga jika hasil pemetaan strategi SI/TI di implmentasikan, kedepanya akan berpengaruh dalam perbaikan pada model bisnis saat ini menjadi lebih baik, seperti terlihat pada Gambar 4.

\subsection{Raod map}

Berdasarkan pemetaan aplikasi dalam portfolio kedepan yang di usulkan, selanjutnya dibuat sebuah roadmap kegiatan rencana strategi SI/TI yang disusun kedalam tahapan-tahapan yang berkesinambungan. Roadmap kegiatan rencana strategi merupakan dokumen yang bersifat dinamis dengan tetap dapat disesuaikan dengan kebijakan perusahaan [5].

Tabel 10

\section{Roadmap}

\begin{tabular}{|c|c|c|c|}
\hline Tahap ke 1 & Tahap ke 2 & Tahap ke 3 & Tahap ke 4 \\
\hline $\begin{array}{c}\text { Sosialisasi } \\
\text { peanfaatan SI/TI }\end{array}$ & & & \\
\hline $\begin{array}{c}\text { Peanfaatan digital } \\
\text { marketing }\end{array}$ & & & \\
\hline & & & \\
\hline & $\begin{array}{c}\text { Pembangunan SI } \\
\text { berbasis Web } \\
\text { (sesuai usulan) }\end{array}$ & Implementasi SI & \\
\hline & Berbasis Web & \\
\hline & & Perancangan DIS & \\
\hline & & & \\
\hline & & & Pengebangan \\
\hline
\end{tabular}

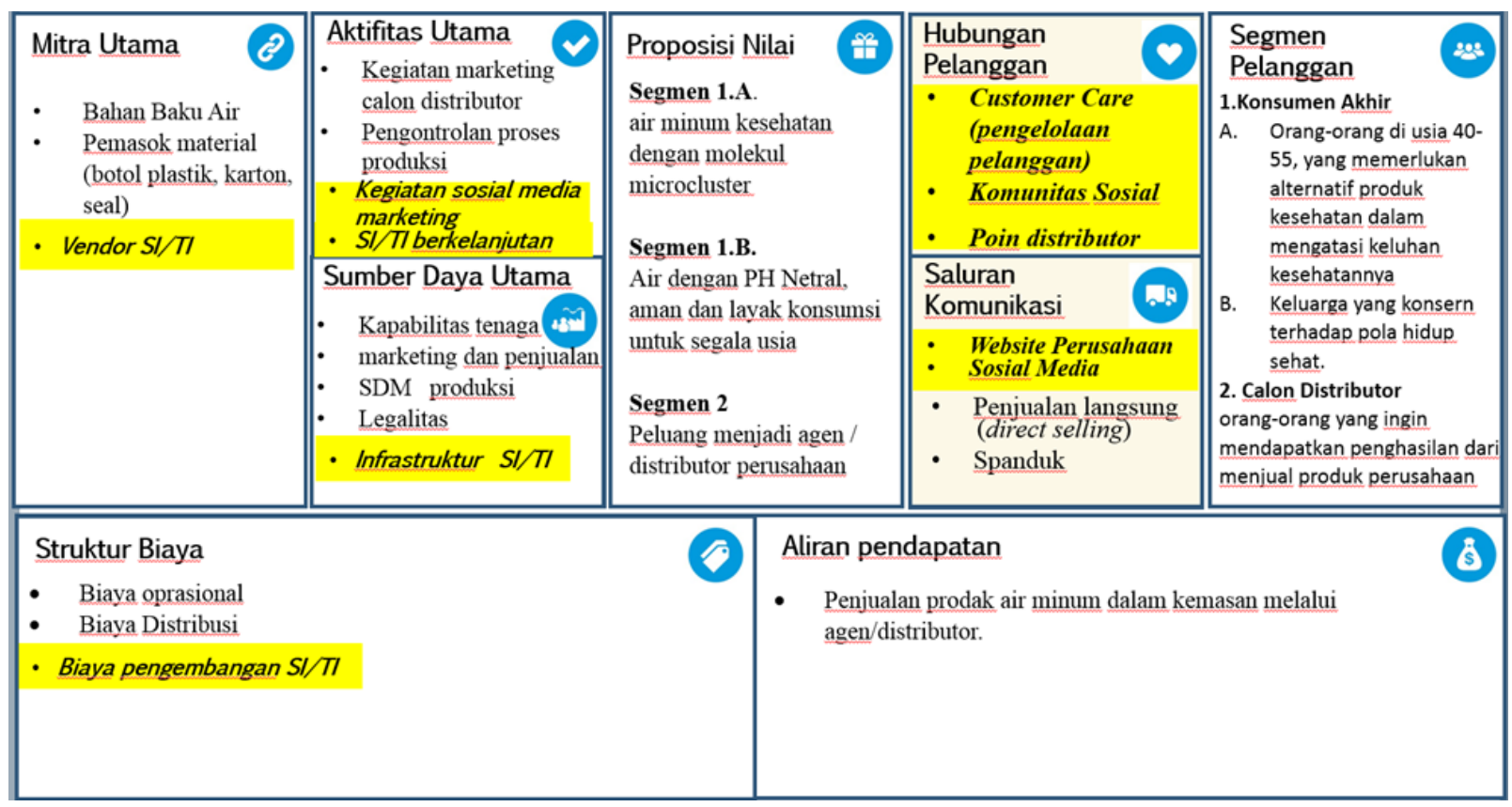

Gambar 4. Perbaikan Model Bisnis Perusahaan

\section{Kesimpulan}

Berdasarkan hasil analisa model bisnis perusahaan dan analisa empat lingkungan perusahaan dengan metode Ward \& Peppard, maka dapat disimpulkan bahwa :

1. hasil peneltian ini menunjukan bahwa dengan dibuatnya perencanaan strategis SI/TI, mempengaruhi model bisnis perusahaan menjadi lebih baik, yang berdampak terhadap terciptanya keunggulan bersaing pada perusahaan.

2. portofolio aplikasi yang dihasilkan dapat mempermudah perusahaan dalam menentukan SI/TI mana yang paling tepat dan harus disegerakan dalam menghadapi persaingan bisnis yang di hadapi.

3. dengan adanya dokumen usulan rencana strategis yang dihasilkan dapat dijadikan dasar dan acuan perusahaan 
untuk pengelolaan SI/TI yang sesuai dengan kebutuhan perusahaan dan dapat memberikan arah bagi pengembangan SI/TI yang mampu mendukung keunggulan bersaing perusahaan secara berkelanjutan.

\section{Referensi}

[1] M. A. Amna, "Home: Industri Air Minum Kemasan Indonesia Bisa Jadi yang Terbesar di ASEAN," 26 Ferruari 2016. [Online]. Available: http://industri.bisnis.com/read/20160226/43/522798/ind ustri-air-minum-kemasan-indonesia-bisa-jadi-yangterbesar-di-asean.

[2] K. C. Laudon dan J. P. Laudon, Sistem Informasi Manajemen (mengelola perusahaan digital), Jakarta: Saleba epat, 2015.

[3] J. Hartono, Sistem informasi Strategik untuk keunggulan kompetitif, Ed. II penyunt., Yogyakarta: Penerbit ANDI, 2006.

[4] L. M. Simanjutak, "Rencana Strategi Sistem Informasi/Teknologi Informasi Menggunkan Ward Dan PepparD," 2017.

[5] J. K. Muslim, "Perancangan Rencna Strategis Sistem Informasi dan Teknologi Informasi Menggunakan Model Ward\&Peppard dan Evolusi Informasi,” p. 27, 2013.

[6] Y. Septiana, ").Perencanaan Strategis SI/TI dengan Pendekatan Ward \& Peppard Model(Studi Kasus: Klinik Inti Garut).," Wawasan Ilmiah, vol. 8, p. 2, 2017.

[7] D. E. Wijaya, "Peranan Inovasi Produk Terhadap Competitive Advantage Melalui Business," AGORA, vol. 5, no. 3, 2017.

[8] L. E. Wijaya dan . R. Indriyani, "Analisis Business
Model Canvas Pada Cv. Kayu Murni," Agrora, vol. 4, no. 2, 2016.

[9] D. L. dan DKK, "Model Dasar Pengembangan Business Model Canvas," Jurnal Sains Dan Seni Its, vol. 6, no. 2, 2017.

[10] Tim PPM Manajemen, Business Model Canvass,Penerapan di Indonesia, Jakarta: PPM, 2012.

[11] D. J. Teece, "business strategy and innovation," dalam Business Models, Elsevier Ltd, 2010.

[12] A. Osterwalder dan Y. Pigneur, Business Model Generation, Jakarta: PT Elex Media Komputindo, 2017.

[13] F. Rangkuti, "Analisis SWOT," Jakarta, Gramedia, 2013, p. 83.

[14] R. S. Kaplan dan D. P. Norton, Balanced Scorecard : menrapkan strategi menjadi aksi, Jakarta: Erlangga, 2000.

[15] B. D. H. F. Annas Wahyu Purwanto, "Penyusunan Tata Kelola Teknologi Informasi Bagi Pemerintah Daerah Menggunakan Framework Cobit 5 (Studi Kasus: Kabupaten Cilacap)," Jurnal Penelitian Pos dan Informatika, vol. 3, no. 2, pp. 189-203, 2122013.

[16] J. Ward dan J. Peppard, Strategic Planning for Information Sytem, Third Edition penyunt., New York: John Wiley \& Sons Ltd, 2002.

[17] M. J. Earl, Information System Strategy Formulation, Hirshheim, Penyunt., New York: Jhon Wiley \& Son Ltd, 1987. 